showed no response to naloxone. Three months later he was admitted in respiratory failure refractory to all treatment. Necropsy showed chronic bronchitis, bullous emphysema, and right ventricular hypertrophy. The intercostal muscles were thin and fibrous, and histology of these and the diaphragm and psoas showed changes of chronic denervation. Histology of the spinal cord was not obtained.

\section{Discussion}

Naloxone reverses the apnoeic response to hypoxia in neonatal rabbits ${ }^{2}$ but, even in large doses, has no effect on respiration in hypoxic man. ${ }^{3}$ Respiratory failure in this patient was thought to be caused by a combination of chronic airflow obstruction and weakness of the respiratory muscles (possibly due to chronic spinal muscular atrophy). ${ }^{4}$ Intravenous naloxone produced an increase in minute ventilation and general agitation when he was acutely ill. The increase in oxygen saturation was greater than expected for the increase in ventilation, suggesting improved ventilation-perfusion matching, but the response occurred only in the acute illness.

These findings suggest that there may be overproduction of, or increased sensitivity to, endorphins in acute respiratory failure. Naloxone is beneficial in shock, ${ }^{5}$ the postulated mechanism being that endorphins inhibit the interaction of catecholamines with their receptors. Such an action might account for the changes in ventilation-perfusion balance in our patient.

Requests for reprints should be sent to Dr J Ayres, Department of Thoracic Medicine, Guy's Hospital, London SE1 9RT.

\section{References}

1 Santiago TV, Remolina C, Scoles V, Edelman NH. Endorphins and the control of breathing. $N$ Engl $\mathcal{F}$ Med $1981 ; 304: 1190-5$

2 Grunstein MM, Hazinski TA, Schlueter MA. Respiratory control during hypoxia in newborn rabbits: implied action of endorphins. $\mathcal{F} A p p l$ Physiol 1981;51:122-30.

${ }^{3}$ Fleetham JA, Clarke H, Dhingra S, Chernick V, Anthonisen NR. Endogenous opiates and chemical control of breathing in humans. Am Rev Respir Dis 1980;121:1045-9.

${ }^{4}$ Haas H, Johnson LR, Gill TH, Armentrout TS. Diaphragm paralysis and ventilatory failure in chronic proximal spinal muscular atrophy. $A m$ Rev Respir Dis $1981 ; 123: 465-76$.

5 Anonymous. Naloxone for septic shock. Lancet 1981 ;i:538-9.

(Accepted 8 fanuary 1982)

\title{
Medial arterial calcification and diabetic neuropathy
}

\author{
M E EDMONDS, N MORRISON, J W LAWS, P J WATKINS
}

\begin{abstract}
$X$-ray examinations of the feet, knees, and hands were performed on 20 diabetics with severe neuropathy and 20 diabetics with no evidence of neuropathy but with a similar mean age and duration of diabetes. All were under 53 years old with no clinical evidence of peripheral vascular disease. Medial arterial calcification was much more common and extensive in the patients with neuropathy, occurring in the feet in 15 and in the hands in eight compared with in four $(p<0.001)$ and none $(p<0.001)$ of the controls respectively. Although there was some correlation between calcification and both proteinuria $(p<0.05)$ and proliferative retinopathy $(p<0.02)$, the association between calcification and neuropathy (p $<0.001)$ was much stronger.
\end{abstract}

Neuropathy, with sympathetic denervation of the smooth muscle of the tunica media, may be important in the aetiology of medial arterial calcification.

\section{Introduction}

Medial arterial calcification, otherwise known as Monckeberg's sclerosis, ${ }^{1}$ was described in diabetics in $1924,{ }^{2}$ but its aetiology and importance remain unknown. It is easily detected on $x$-ray films by its classical "pipe-stem" or "tramline" appearance (see fig 1). Previous observations have indicated that the calcification

\footnotetext{
Diabetic Department and Radiology Department, King's College Hospital, London SE5 9RS

M E EDMONDS, MB, MRCP, research fellow and honorary lecturer N MORRISON, MB, FRCR, senior registrar in radiology

J W LAWS, FRCP, FRCR, consultant radiologist

P J WATKINS, MD, FRCP, consultant physician
}

is predominantly related to the age of the patient and the duration of diabetes. ${ }^{3-5}$ During a recent study of blood flow in the foot in patients with neuropathy, however, it was noted that medial wall calcification was particularly common in diabetics with severe neuropathy. ${ }^{6}$ There were two aims of the present study: firstly, to determine whether medial wall calcification was a specific complication of diabetes, not just related to age and duration of disease, and, secondly, to consider its relation to neuropathy, which could be important in its pathogenesis.

\section{Patients and methods}

The presence of calcification was determined in two groups of patients, the first consisting of 20 diabetics with neuropathy and the

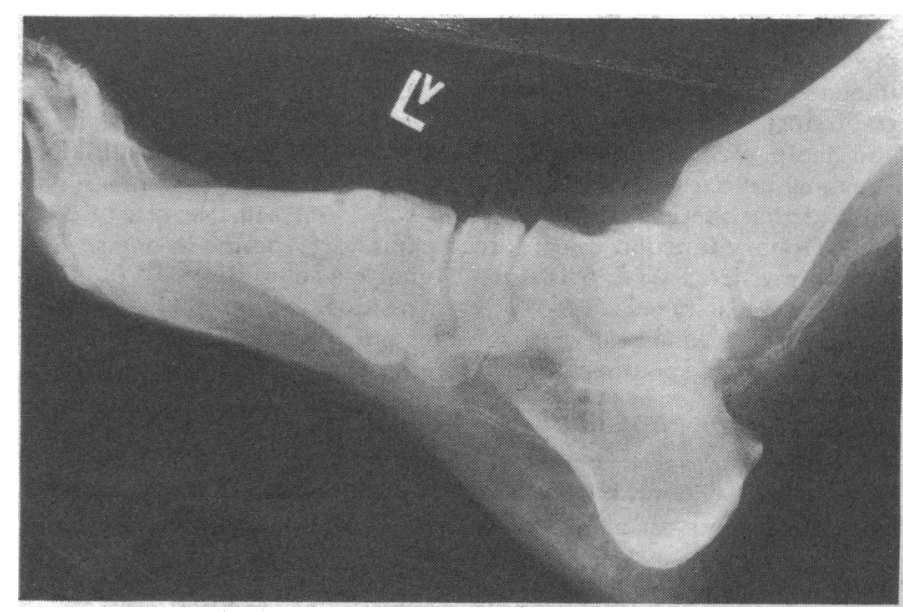

FIG 1-Lateral view of foot showing characteristic "tramline" appearance of medial arterial calcification. 
second of 20 diabetics with no clinical evidence of neuropathy. The criteria for entry into the first group were as follows: each patient should have substantial somatic and autonomic neuropathy as indicated by a history of neuropathic ulceration (with or without the presence of Charcot's arthropathy) and an abnormal beat-to-beat variation with deep breathing ${ }^{7}$; and they should be under 53 years of age, have palpable posterior tibial and dorsalis pedis pulses, and have serum calcium, phosphate, and creatinine concentrations within normal limits. The first 20 diabetics with neuropathy visiting the clinic who fulfilled these conditions were entered into the study.

The criteria for entry into the control group were as follows: each patient should have no clinical evidence of neuropathy (that is, ankle jerks were present and beat-to-beat variation of heart rate was within normal limits) and should be under 53 years of age with palpable pulses and normal serum biochemistry. These control patients were selected so that the distributions of age and duration of diabetes were similar in the two groups.

Table I shows the clinical details of the patients with neuropathy. Eight had Charcot's arthropathy in the foot or ankle, and two had undergone unilateral above-knee amputations for severe sepsis associated with ulceration. The mean age was $39.0 \pm S D 9.3$ years (range 22-52 years) and the mean duration of diabetes $20 \cdot 7 \pm 8 \cdot 4$ years. The mean beat-to-beat variation of heart rate was $4.41 \pm$ 2.3. The mean serum concentration of calcium was $2 \cdot 43 \pm 0 \cdot 10$ $\mathrm{mmol} / 1(9 \cdot 7 \pm 0.4 \mathrm{mg} / 100 \mathrm{ml})$, of phosphate $0.95 \pm 0.20 \mathrm{mmol} / 1$ $(2.9 \pm 0.6 \mathrm{mg} / 100 \mathrm{ml})$, and of creatinine $79.7 \pm 18.6 \mathrm{mmol} / \mathrm{l}(901$ $\pm 210 \mathrm{mg} / 100 \mathrm{ml}$ ). Proteinuria was assessed by a 24-hour urine collection: 13 of the patients with neuropathy had considerable proteinuria as indicated by a 24-hour urine value of $200 \mathrm{mg}$ or more.

In the controls the mean age was $38.3 \pm 7.6$ years (range 26-52 years) and the mean duration of diabetes $19 \cdot 9 \pm 7 \cdot 8$ years. The mean serum concentration of calcium was $2 \cdot 44 \pm 0.1 \mathrm{mmol} / 1$ (9.8 \pm 0.4 $\mathrm{mg} / 100 \mathrm{ml})$, of phosphate $0.90 \pm 0.13 \mathrm{mmol} / 1(2 \cdot 8 \pm 0.4 \mathrm{mg} / 100 \mathrm{ml})$, and of creatinine $84.5 \pm 14.3 \mathrm{mmol} / 1(956 \pm 161 \cdot 7 \mathrm{mg} / 100 \mathrm{ml})$. Six of the subjects had background retinopathy and none had proteinuria.

The presence or absence of calcification in the limbs of all 40 patients was not known before the start of the study.

Non-magnified radiographs of the hands, knees, feet, and ankles were obtained in all patients using Kodak Ortho G Xomatic film in Kodak HD Xomatic cassettes at $100 \mathrm{~cm}$ from an $x$-ray tube with a $0.6 \mathrm{~mm}$ focal spot. In the hands a standard posteroanterior projection was obtained on $24 \times 30 \mathrm{~cm}$ film to include proximal phalanges and distal forearms; exposure factors were $56-60 \mathrm{kV}$ peak, $10 \mathrm{~mA} \mathrm{~s}$. A standard posteroanterior projection of both feet was obtained on $24 \times 30 \mathrm{~cm}$ film; exposure factors were $60 \mathrm{kV}$ peak, 8-13 mA s. In addition true lateral views were obtained of each foot excluding the toes but including as much of the leg as would fit on $24 \times 30 \mathrm{~cm}$ films; exposure factors were $60-65 \mathrm{kV}$ peak, $13 \mathrm{~mA}$ s. Finally, true lateral views were obtained of each knee; exposure factors were $56-65 \mathrm{kV}$ peak, 8-10 mA s.

Films were examined using a standard viewing box with the aid of
TABLE II-Prevalence of neuropathy, proliferative retinopathy, and proteinuria in patients with calcification compared with patients without calcification, and significances of differences

\begin{tabular}{|c|c|c|c|c|c|c|}
\hline \multirow[b]{3}{*}{$\begin{array}{l}\text { Patients with calcification } \\
\text { Patients without calcification }\end{array}$} & \multicolumn{2}{|c|}{ Neuropathy } & \multicolumn{2}{|c|}{$\begin{array}{l}\text { Proliferative } \\
\text { retinopathy }\end{array}$} & \multicolumn{2}{|c|}{ Proteinuria } \\
\hline & Preser & bsent & Preser & Absent & Preser & Absent \\
\hline & $\begin{array}{r}16 \\
4\end{array}$ & $\begin{array}{r}4 \\
16\end{array}$ & $\begin{array}{l}9 \\
1\end{array}$ & $\begin{array}{l}11 \\
19\end{array}$ & $\begin{array}{r}10 \\
3\end{array}$ & $\begin{array}{l}10 \\
17\end{array}$ \\
\hline Significance of difference* & \multicolumn{2}{|c|}{$\mathrm{p}<0.001$} & \multicolumn{2}{|c|}{$\mathrm{p}<0.02$} & \multicolumn{2}{|c|}{$p<0.05$} \\
\hline
\end{tabular}

${ }^{*} \chi^{2}$ test with Yates's correction.

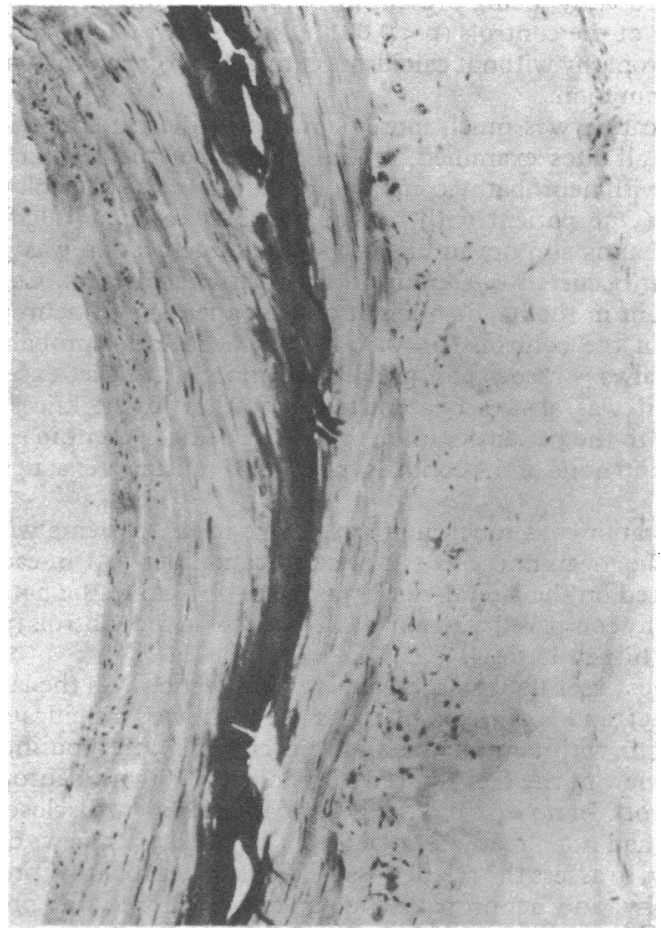

FIG 2-Part of cross-section of posterior tibial artery in patient with neuropathy. Haematoxylin and eosin stain indicated calcification within medial wall. $\times \mathbf{4 0}$ (original magnification).

TABLE I-Clinical details of patients with neuropathy, with extent of calcification (mean of both limbs) $(++$ indicates $>2.5 \mathrm{~cm}$ and + indicates $\leqslant 2.5 \mathrm{~cm}$ calcification per $\operatorname{limb}$ )

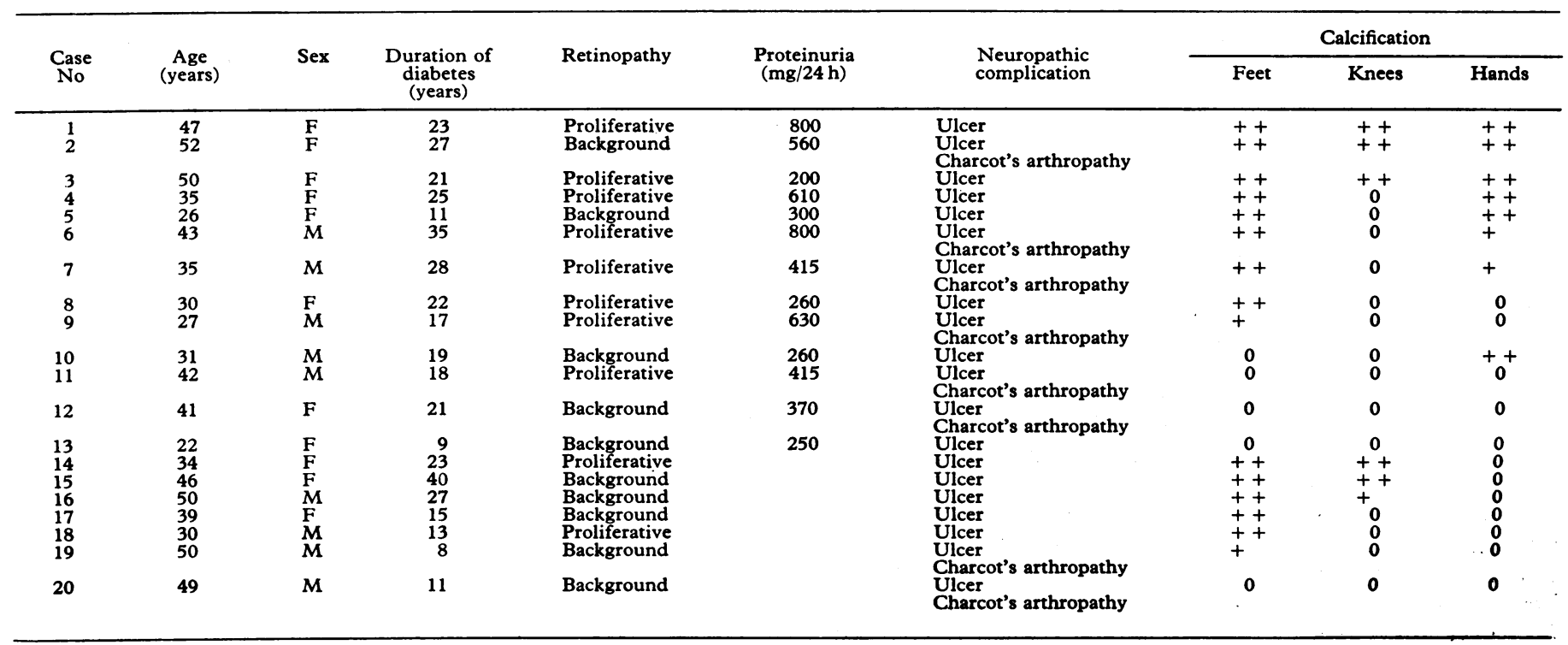


a $\times 2$ magnifying glass. Medial arterial calcification was recognised by the fine uniform appearance of two parallel lines, with the characteristic "tramline" appearances (fig 1). The extent of medial calcification was expressed in centimetres of affected artery for each limb and then the mean calculated.

One patient with neuropathy with radiological evidence of medial arterial calcification later underwent below-knee amputation because of gross sepsis of the foot. Histological study of the posterior tibial artery confirmed the presence of medial calcification (fig 2).

In assessing the statistical significance of observations the $\chi^{2}$ test with Yates's correction and, when appropriate, Fisher's exact probability test were used.

\section{Results}

Calcification was much more common and extensive in the patients with neuropathy, being present in 16 of these patients compared with only four of the controls ( $p<0.001 ; \chi^{2}$ test). Two of the four patients with neuropathy without calcification had undergone unilateral aboveknee amputation.

Calcification was much more common in the patients with neuropathy at all sites examined. It was present in the feet in 15 of the patients with neuropathy compared with four of the controls $(p<0.01$; $\chi^{2}$ test). (One patient with neuropathy had vascular calcification in only his hands and not in his feet.) When calcification was present in the feet it occurred bilaterally in all but three patients. Calcification was present in the hands of eight of the patients with neuropathy but in none of the controls $(p=0 \cdot 00164$; Fisher's exact probability test) and was always associated with calcification in the feet except in one patient; it was always bilateral. Calcification in the knees was also exclusive to the patients with neuropathy, being present in six of these patients and none of the controls $(p=0.0101$; Fisher's exact probability test).

Calcification was much more extensive in the patients with neuropathy. The mean linear extent of calcification per foot in each patient (as detected on the lateral view) was $8.71 \pm 9.7 \mathrm{~cm}$ in the patients with neuropathy compared with only $0.54 \pm 1.5 \mathrm{~cm}$ in the controls $(\mathrm{p}<0.001$; Mann-Whitney U test).

The most useful view for detecting calcification was the lateral view of the feet and ankles. While this view showed calcification in 19 patients ( 15 with neuropathy and four controls), the routine posteroanterior view of the feet showed it in only 11 (10 with neuropathy and one control). In no case did the posteroanterior view disclose calcification that had not already been detected on the lateral views of the feet.

Finally, to assess the relative associations of neuropathy, proliferative retinopathy, and nephropathy (as judged by appreciable proteinuria) with calcification we divided all 40 patients into those with and without calcification. Calcification was much more strongly associated with neuropathy than with proliferative retinopathy or proteinuria (table II).

\section{Discussion}

We found that medial wall calcification is a specific complication of diabetes not merely related to age and duration of diabetes as previously described but strongly associated with neuropathy, which may be related to its aetiology. We also showed that the most useful and sensitive means of screening for medial calcification is a lateral view of the feet and ankles. Although a link between calcification and neuropathy has not been sought before, our results agree with observations made in the course of other studies. In two large series of cases of Charcot's arthropathy vascular calcification was found in $90 \%{ }^{8}$ and $78 \%{ }^{9}$ respectively. Although medial wall calcification may be a normal feature of aging, with particular prominence after the fifth decade, ${ }^{10}$ we studied young and middle-aged subjects, in whom vascular calcification is usually absent.

Medial wall calcification is common in chronic renal failure, in which derangements of calcium and phosphorus metabolism ${ }^{11}$ and uraemic damage to the medial elastic fibres have been incriminated. ${ }^{12}$ All our subjects, however, had normal serum creatinine, calcium, and phosphate concentrations even though 13 had considerable proteinuria indicating diabetic nephropathy. Ferrier could find no relation of calcification to nephropathy. ${ }^{3}$ Moreover, when patients with proteinuria were excluded in our study six of the remaining seven patients with neuropathy had extensive calcification. Although there was a relation between calcification and nephropathy $\left(\mathrm{p}<0.05 ; \chi^{2}\right.$ test), the association between calcification and neuropathy $\left(\mathrm{p}<0.001 ; \chi^{2}\right.$ test $)$ was much stronger (table III).

The finding of an association does not necessarily imply causation, and it might be speculated that calcification is a manifestation of diabetic microvascular disease. The media of most arteries depends for its nutrition on the vasa vasorum, which enter the outer layers of the media via the adventitia. ${ }^{13}$ Possibly these vessels are affected by microangiopathy, and the association with retinopathy would support this.

Neuropathy might, however, be important in the aetiology of medial calcification. Arterial calcification is initiated within senescent atrophic smooth muscle, ${ }^{14}$ the autonomic nerve supply to smooth muscle is reduced in old age, ${ }^{15}$ and sympathectomy causes atrophy of medial smooth muscle with foci of necrosis. ${ }^{10}$ Recent work has shown that morphological changes occur in smooth muscle after autonomic denervation ${ }^{17}$ similar to the welldescribed atrophic changes after denervation of striated muscle, and long-term sympathetic denervation leads to structural changes in the smooth-muscle wall of arteries. ${ }^{18}$

Thus we conclude that medial arterial calcification is a specific complication of diabetes and is associated with neuropathy, which may be an important aetiological factor. The calcification is most easily detected by lateral $x$-ray examination of the feet and ankles.

We are grateful for co-operation from the radiology department at this hospital, and in particular for the skilled radiography of Mrs A Womack and Miss $\mathrm{H}$ Baxter.

MEE is supported by a grant from the King's Voluntary Research Trust Fund.

\section{References}

1 Monckeberg JG. UUber die reine Mediaverkalkung der Extremitatenarterien und ihr Verhalten zur Arteriosklerose. Virchows Arch [Pathol Anat] $1903 ; 171: 141-67$

${ }^{2}$ Bowen BD, Koenig EC, Viele A. A study of the lower extremities in diabetes as compared with non-diabetic states from the standpoint of $\mathrm{X}$-ray findings, with particular reference to the relationship of arteriosclerosis and diabetes. Bulletin of the Buffalo General Hospital 1924 ;2: 35-41.

${ }^{3}$ Ferrier TM. Radiologically demonstrable arterial calcification in diabetes mellitus. Australasian Annals of Medicine 1967;13:222-6.

4 Christensen NJ. Muscle blood flow, measured by xenon and vascular calcification in diabetics. Acta Med Scand $1968 ; 183: 449-54$.

5 White P. Natural course and prognosis of juvenile diabetes. Diabetes $1956 ; 5: 445-50$.

${ }^{6}$ Edmonds ME, Roberts VC, Watkins PJ. Blood flow in the diabetic neuropathic leg. Diabetologia (in press).

7 Wheeler T, Watkins PJ. Cardiac denervation in diabetes. Br Med F 1973; iv:584-6.

${ }^{8}$ Sinha S, Munichoodappa CS, Kozak GP. Neuroarthropathy (Charcot joints) in diabetes mellitus. Medicine (Baltimore) $1972 ; 51: 191-210$.

${ }^{9}$ Clouse ME, Gramm HF, Legg M, Flood T. Diabetic osteoarthropathy. $A \mathcal{R}$ 1974;121:22-34.

${ }^{10} \mathrm{Lie}$ JT. The structure of the normal vascular system and its reactive changes. In: Juergens JL, Spittel JA, Foxenbun JF II, eds. Peripheral vascular diseases. London: W B Saunders Ltd, 1980:51-81.

11 Parfitt MA. Soft tissue calcification in uraemia. Arch Intern Med 1969; $124: 544-55$.

12 Deluca HF, Avioli LV. Renal osteodystrophy. In : Black DAK, Jones NF. Renal disease. 4th ed. Oxford: Blackwell, 1979:766-803.

13 Helstad DD, Marcus ML. Role of vasa vasorum in nourishment of the aorta. Blood Vessels 1979;16:225-8.

14 Morgan AJ. Mineralized deposits in the thoracic aorta of aged rats: ultrastructural and electron probe X-ray microanalysis study. Exp Gerontol 1980;5:563-73.

15 Botár J. The autonomic nervous system. Budapest: Akadémiai Kiadó, 1966.

${ }^{16}$ Kerper AH, Collier WD. Pathological changes in arteries following partial denervation. Proc Soc Exp Biol Med 1926;24:493-4.

17 Armaly MF. Denervation of ciliary muscle and iris sphincter following resection of the ciliary ganglion. Trans Am Ophthalmol Soc 1968;66: 475-501.

${ }^{18}$ Bevan RD, Tsuru $H$. Long term denervation of vascular smooth muscle causes not only functional but structural change. Blood Vessels 1979; 16:109-12.

(Accepted 4 January 1982) 